\title{
EDITORIAL. NUEVOS ESTUDIOS DEL DISEÑO DE INTERIORES Y DEL MUEBLE
}

\author{
Ana María Fernández García \\ Universidad de Oviedo
}

Si abríamos el primer número de la revista Res Mobilis sumándonos al "ánimo de empezar" del mecenas del templo salmantino de San Boal, afrontamos el segundo con el deseo de perseverar, voluntad de mejorar y perfeccionar, así como confianza renovada en el interés de los estudios sobre el mueble, los objetos artísticos, la decoración y el diseño de interiores.

Respondiendo al carácter internacional e interdisciplinar con que nació la publicación, los trabajos ofrecidos en esta ocasión presentan investigaciones de diferentes ámbitos geográficos y, sin limitarse al marco de la Historia del Arte, incorporan interpretaciones que llegan de la mano de otras disciplinas o enfoques; desde la literatura, la arquitectura o la restauración hasta la creación actual. Esos múltiples puntos de vista contribuirán a ofrecer, paulatinamente, una visión cada vez más global y completa sobre los espacios y amueblamientos, sobre el propio concepto de habitar, que ha definido y define aún hoy nuestros interiores como escenarios de la vida pública y privada. En cuanto a la dimensión internacional, se suma ahora el portugués a las lenguas empleadas en artículos y reseñas, y con ella el deseo de apertura a la realidad objeto de estudio específico en la Península Ibérica e Iberoamérica.

Sabedores de que la calidad de las investigaciones publicadas es la mejor garantía de la continuidad de la revista, hemos apostado por varios criterios de excelencia. Se ha ampliado la lista de revisores a doble ciego y, cuando se producen diferencias de criterio, se ha apostado por una tercera revisión. En todos los casos se ha cuidado la justificación de la decisión de las revisiones, así como el traslado a los autores de propuestas de modificación o sugerencias para modificaciones formales o conceptuales. Creemos que ésta es vía fecunda para la mejora de los estudios y hace de la revisión una herramienta de ayuda para los autores, al servicio del rigor y la calidad. En el mismo sentido, la lista de revisores está ya publicada, para mejorar la transparencia de la trazabilidad de la publicación. En la misma línea hemos incorporado también una sección nueva en la página inicial, que incorpora los artículos más citados y que se pretende ir 
renovando a medida que haya datos de interés.

Otra novedad que hemos incluido en este segundo número ha sido el de reseñas de exposiciones para acoger en la publicación exhibiciones relacionadas con el mueble y el diseño de interiores. La revista puede ser un foro adecuado para estas reseñas ayudando a que no se pierda en muchos casos su memoria, por encima del espacio temporal de su celebración.

En cuanto a los contenidos concretos de este número, y sin ánimo de una síntesis prolija que el lector puede alcanzar a partir de los resúmenes que abren cada artículo, el formato de revista permite una enriquecedora heterogeneidad, siempre en el marco de intereses de Res Mobilis. Hay investigaciones sobre el amueblamiento urbano de La Habana, un análisis detallado de los dibujos de muebles del Museo Lázaro Galdiano que suponen una fuente inédita de modelos, un recorrido por la saga de marqueteros barceloneses Sagarra que ofrece una completa biografía de empresa, una interesante reconstrucción del interior del Centro Mercantil de Oviedo, una monografía sobre la decoración del Hotel Mandarin de Barcelona de Patricia Urquiola, o un análisis pormenorizado de la serie de oficina Sintex, diseñada por Menéndez Hevia que fue durante años el equipamiento por excelencia de las entidades bancarias españolas. Pero el número tiene otras aportaciones igualmente relevantes, como la caracterización de las principales casas dedicadas al amueblamiento en La Coruña a partir de las reformas del teatro Rosalía de Castro, el estudio del rol como difusora de tipologías de mobiliario de la revista portuguesa A Construcção Moderna, un análisis de la dicotomía entre funcionalidad y confort en la decoración de interiores lisboeta en el tránsito al siglo XX con una clara influencia francesa, un original estudio sobre las primeras neveras en España o, por último, una reflexión sobre el patrón simbólico de la casa arquetípica en las creaciones contemporáneas. Creemos que la riqueza de matices, lugares y enfoques de este número es elocuente.

Más de mil visitas a la web de la revista y las más de trescientas descargas directas de algunos de los artículos del primer número constituyen un buen estímulo para continuar y un refrendo a la apuesta editorial. Agradecemos de forma sincera el esfuerzo y la extraordinaria profesionalidad de los revisores y la confianza que demuestran los distintos autores; ellos son el cimiento de un proyecto que aspira a mantener el interés del público especializado y confía incluso en nuevas dimensiones en un futuro próximo. 